\title{
Transmedia, documental interactivo y educación: análisis de casos
}

Transmedia, interactive documentary and education: case analysis

Maximiliano Ignacio de la Puente maxidelapuente@gmail.com

http://orcid.org/0000-0002-2645-8867

Universidad Nacional de Moreno/

Universidad Nacional de las Artes (Argentina)

\section{Resumen}

En este trabajo reflexionaré sobre mi experiencia en la carrera de Comunicación Social de la Universidad Nacional de Moreno, en el marco del Taller de Transmedia y Documental Interactivo, del que fui profesor titular durante 2015 y 2016. Me referiré también al trabajo en el marco del Taller de proyectos documentales transmedia, perteneciente a la Maestría en Periodismo documental de la Universidad Nacional de Tres de Febrero, que dicté entre los meses de octubre y noviembre de 2016. Analizaré dos de las producciones más destacadas de los estudiantes en esos ámbitos, con el fin de reflexionar sobre los usos y las posibilidades que el transmedia tiene en el ámbito educativo.

Palabras clave: transmedia; documental interactivo; educación. 


\begin{abstract}
In this paper I will reflect on the experiences I carried out in the career of Social Communication of the National University of Moreno, within the framework of the subject: Workshop of Transmedia and Interactive Documentary, of which I was a professor, during 2015 and 2016
\end{abstract}

Keywords: transmedia; interactive documentary; education.

Las tecnologías digitales de la información y la comunicación, junto con los entornos mediáticos multiplantallas y la hibridación y diseminación de dispositivos, formatos y lenguajes, han permitido ampliar en las últimas décadas el universo representativo, es decir, aquello que es enunciable, mostrable y visible, no sólo en lo que se refiere al campo del documental audiovisual sino también en el periodismo y las narrativas televisivas.

En este trabajo reflexionaré sobre las narrativas transmedia de no ficción desde la educación universitaria. Este es un campo en gran medida vacante, puesto que, si bien es cierto que la bibliografía que se refiere al universo de las narrativas transmedia es cada vez más abundante, son escasos los trabajos de investigación sobre estas narrativas aplicadas a la educación. En este sentido, tal como sostiene María del Mar Grandío-Pérez (2016), se torna imperiosamente necesario el desarrollo y la consolidación de la alfabetización transmedia en el ámbito de la investigación y la docencia, así como la creación de guías de trabajo, manuales, ejercicios prácticos para desarrollar en clase y la visibilización del contenido generado por los estudiantes, con el fin de estimular producciones futuras. Este es precisamente uno de los objetivos centrales del presente trabajo, es decir, reflexionar sobre prácticas educativas desde la perspectiva de las narrativas transmedia documentales y dar a conocer a la vez trabajos de estudiantes de grado y posgrado, que inspiren desarrollos de investigaciones ulteriores.

Los casos que trataré aquí abordan el universo de estas narrativas aplicadas a disciplinas como la comunicación, la historia, la sociología y la geopolítica contemporánea, de lo que se deduce que el transmedia plantea una perspectiva multidisciplinaria, y que es desde esta mirada transversal "desde donde podemos tratar las nuevas realidades mediáticas y, por extensión, educativas" (Grandío-Pérez, 2016: 89).

Las universidades públicas, en especial aquellas que ofrecen carreras de grado y de posgrado de comunicación y de medios audiovisuales, ocupan un lugar estratégicamente clave en relación a las posibilidades de las narrativas transmedia y sus aplicaciones educativas, y 
también en lo que se refiere a restituir la dimensión político/social de este tipo de narrativas que se encuentran siempre en la encrucijada de ser cooptadas por el mercado y el marketing comunicacional.

La politicidad de los trabajos prácticos que presento aquí se encuentra dada precisamente porque ellos elaboran narrativas que construyen identidades locales, para las que hay muy poca escucha o audibilidad social, como los hechos históricos ocurridos en la localidad de Moreno, que hacen a la identidad colectiva de nuestro país, por un lado, y a la recuperación de las historias de vida de los habitantes de la República Árabe Saharaui Democrática, por el otro. En estas experiencias se recuperan memorias, dispositivos de luchas y acontecimientos pasados y presentes, por lo que la comunicación deviene así política, en la medida en que lo mediático se abre a "otras estéticas y modos de narrar, inscritos en las identidades otras" (Rincón, 2013: 14). Estos trabajos circunscriptos a las narrativas transmedia recuperan historias dejadas de lado por los entramados mediáticos masivos, a la vez que retoman identidades subalternas que carecen de visibilidad pública.

El uso crítico, ético y responsable de las tecnologías de la información y la comunicación, en este escenario caracterizado por la cultura de la convergencia, deviene así en una instancia determinante a la hora de trabajar en el aula, en lo que se refiere a la educación mediática. Las narrativas transmedia demandan un tipo de construcción educativa en la que los estudiantes sean capaces de expresarse en diferentes soportes, medios, pantallas y lenguajes, en vez de ser interpelados como meros receptores pasivos. Los estudiantes deben ser así capaces de "comprender la complementariedad de diferentes textos mediáticos" (Grandío-Pérez, 2016: 95), que incluyen la gráfica, el sonido, las animaciones, las infografías interactivas, el video, el texto escrito, etcétera. El fomento del aprendizaje en el trabajo colaborativo, en la creatividad y en las dinámicas grupales es otro de los atributos de las narrativas transmedia aplicadas a la educación. Una aptitud esencial en la medida en que vivimos en un mundo en el que los tráficos, los préstamos, los intercambios y las hibridaciones están cada vez más a la orden del día, tanto en la escena local como globalizada.

\section{Algunas conceptualizaciones teóricas: el documental interactivo}

En los siguientes apartados abordaremos algunos de los tópicos principales de la cultura de la convergencia y las narrativas transmedia. Empezaremos por el documental multimedia interactivo, que constituye un objeto sumamente complejo, aún en construcción. Tomamos las 
reflexiones de varios de los más destacados especialistas en el tema, centrándonos especialmente en las consideraciones de Arnau Gifreu Castells (2013). Tal como él mismo sostiene, nos encontramos con un objeto inserto en un ecosistema en transformación constante, caracterizado por un entorno digital en rápida evolución. La contaminación y confusión terminológica es tal que ni siquiera existe una única manera para referirse a estos documentales. Conviven así expresiones como "documentales de nuevos medios", "documentales digitales", "documentales en nuevas plataformas", "documentales transmedia", "webdocs" o "webdocumentales", "bases de datos narrativas", "exploraciones interactivas", "visitas virtuales", "ensayos digitales", etcétera.

Desde sus inicios, el género documental se ha constituido en una de las herramientas más eficaces para contar historias de no ficción sobre "la realidad". A lo largo del siglo XX y en lo que va del $X X I$, el género ha pasado de una búsqueda de representación más o menos "transparente" de lo real a desarrollar experiencias que evidencian explícitamente la subjetividad del realizador, en donde la relación con el referente externo a las películas se desdibuja por completo. El documentalista irrumpe, marca, deja huellas en el espacio fílmico/real, realiza un acto performativo que incide sobre este último. Por su parte, la posibilidad de que los usuarios puedan elegir y adquieran control sobre el propio documental, (un espacio reservado anteriormente en exclusividad para el realizador), se profundiza con el desarrollo de los medios interactivos, los mundos virtuales y los videojuegos. El espectador interactivo puede asumir en algunos casos el rol de co-creación de la propia experiencia documental, aunque por lo general ocupando un lugar subsidiario. Por ejemplo, en lugar de editar una película de manera lineal, un documentalista puede crear una base de datos de clips de vídeo y entrevistas, a través de la cual un interactor podrá navegar con el uso de una interfaz gráfica de usuario, situación que permite que este último profundice en asuntos de su propio interés, generando así una experiencia documental muy personal. En este escenario, el espectador y/o jugador es también un usuario y un lector. En el marco del hipertexto, el documentalista ya no posee el dominio total sobre el sentido final de su producto. En el documental interactivo puede sustituirse una estructura dramática clásica que se apoya fuertemente en un inicio, un cuerpo central y un final, por nudos temáticos que se utilizan para desarrollar el tema y contextualizar, narrar los antecedentes del caso, incluir información complementaria y documentar el hecho en cuestión. Estos bloques pueden combinarse con núcleos argumentativos o de opinión, a través de enlaces a blogs, redes sociales, etc. El documental interactivo asume la forma de un "metagénero" que contiene formatos, discursos y múltiples experiencias de diversos usuarios. 


\section{Narrativas transmedia}

Se utiliza el término "narrativas transmedia" para referirse a un tipo de historias o producciones culturales que expanden el universo narrativo, a través de distintos lenguajes (verbales, audiovisuales, etcétera), y de plataformas mediáticas. Y también en producciones en las que, como característica fundamental, se encuentra el papel de los espectadores/prosumidores (usuarios + consumidores) para esa expansión. Algunos ejemplos son: Matrix, Lost, Star Wars, Harry Potter, 24, entre muchos otros. Los productores y creadores de relatos transmediáticos se proponen convertir un producto en una marca. $Y$ generar consiguientemente una expansión entre los usuarios, los cuales a su vez se constituyen como actores principales en la producción de nuevos contenidos asociados al universo original (en blogs, wikis, foros, etcétera). Se diversifican además otros productos, (aplicaciones, juguetes, merchandising diverso), y obras derivadas del proyecto original (spin-off).

Una consideración clave para referirse a la narrativa transmedia es que en ella cada medio realiza un aporte significativo y que sólo ese medio puede hacer. Se expanden los relatos, aparecen nuevos personajes y subtramas derivadas de un universo original. Se crea una red que involucra personajes, lugares, tiempos, acontecimientos y medios.

\section{Intertextualidad, multimodalidad, cultura en red}

Henry Jenkins (2008) considera que lo más importante a la hora de hablar de una obra transmedia, (es decir, que estemos efectivamente ante un texto transmedia), es que ella propone una intertextualidad radical, donde todas las partes se conectan. Esta intertextualidad (es decir, el vínculo que un texto mantiene con otros, generando una polifonía), se relaciona con el concepto de multimodalidad y también con el hecho fundamental de que la obra transmedia fue diseñada claramente para una cultura en red. No se trata de una mera adaptación de formatos, sino justamente de que cada medio o lenguaje hace su aporte específico. Asimismo cada nueva instancia, en esta dispersión textual, "debe ser lo suficientemente autónoma para permitir un consumo autónomo. O sea, no debes ver la película para entender el videojuego, y viceversa" (Jenkins, 2008). 
Los términos crossmedia, transmedia y producción multiplataforma tienen un sustrato común en cuanto a la producción y a los presupuestos subyacentes que los sostienen. En definitiva estos conceptos hacen hincapié en la construcción de mundos narrativos que se manifiestan a través de diferentes medios y/o plataformas, y se refieren a prácticas de producción de sentido que surgen de historias conformadas por esa mixtura de lenguajes, medios y plataformas. Según Scolari (2013), la hipermediación constituye un proceso de intercambio, producción y consumo simbólico que se desarrolla en un entorno caracterizado por una gran cantidad de sujetos, medios y lenguajes interconectados tecnológicamente de manera reticular entre sí.

\section{Características de las obras transmedia}

Existen algunas características importantes que atañen a las narrativas transmedia. Para mencionarlas, seguimos las definiciones de Henry Jenkins (2008).

Expansión y profundidad: la expansión se refiere a las prácticas de difusión viral en redes sociales y demás plataformas. Con respecto a la profundidad, corresponde al trabajo que realiza el equipo de realización para que la narrativa transmedia encuentre a sus fanáticos, quienes serán los mejores impulsores de la historia.

Continuidad y multiplicidad: el mundo narrativo debe mantener una continuidad en lo que respecta a personajes (características y comportamientos) y al universo narrativo común, en los distintos medios y plataformas en que se desarrolla. Asimismo este aspecto de continuidad confronta con la característica de la multiplicidad, que consiste en la creación de tramas que en un principio aparecen como incongruentes respecto a la trama narrativa primera. Esto sucede por ejemplo en los cómics, donde los personajes son llevados a otras situaciones o interactúan con otros personajes sustraídos de otras historias.

Inmersión y "Extraibilidad": este tipo de narrativas propone experiencias de inmersión, (los videojuegos o experiencias de realidad aumentada son un clásico ejemplo). Y además se ofrecen paralelamente aplicaciones, juguetes, etcétera, que hacen su aporte a la "extraibilidad", es decir permiten extraer ciertas partes del relato y llevarlos a lo cotidiano del espectador/usuario. Con esto el usuario puede seguir expandiendo el relato, al crear sus propias nuevas historias.

Construcción de mundos: las narrativas transmedia construyen y proponen mundos narrativos. En esta construcción se apunta a la creación de un verosímil, de un universo que intenta 
detener la incredulidad por parte del usuario. La instalación de un verosímil se produce al igual que en las narrativas tradicionales, pero a esto se le suma un cierto carácter enciclopédico de este tipo de relatos transmedia. Los detalles de la historia narrada (detalles que hacen a características de los personajes o del mundo construido), pasan a conformar el conocimiento enciclopédico de los seguidores. Más que de hablar sobre historias con una estructura (inicio, nudo y desenlace), se trata de la creación de una atmósfera y de un universo.

Serialidad: la narrativa transmedia continúa una tradición del siglo XIX y principios del siglo XX: la difusión de narrativas seriales. En esa época tuvo un gran auge la literatura de folletines o la literatura de cordel. Estos relatos transmediáticos apuntan a la no linealidad en su construcción, y además no se concentran en un único medio para su difusión. La no linealidad se basa fundamentalmente en el carácter de red hipertextual de estas narrativas.

Subjetividad: en las narrativas transmedia abundan las perspectivas y diversas miradas a causa de la gran cantidad de personajes e historias. Se trata de subjetividades múltiples que se conforman a partir de relatos provenientes de la reformulación y combinación de diversos objetos textuales. Este hecho requiere del usuario/espectador una mayor atención y esfuerzo para la decodificación.

Realización o performance: como ya dijimos, el papel de los espectadores/usuarios es esencial para la expansión de las narrativas transmediáticas. Hay un núcleo duro de seguidores que se constituyen como prosumidores, al producir nuevos textos y contenidos.

Estas breves reflexiones teóricas buscaron introducir algunos conceptos centrales pertenecientes al mundo del transmedia documental. En lo que sigue ahondaré en la descripción y el análisis de las experiencias que llevé a cabo con los estudiantes, en el marco de los espacios curriculares anteriormente mencionados.

\section{Algunos ejercicios básicos de transmedia}

Tanto la dinámica que llevé a cabo en el marco del Taller de Transmedia y Documental Interactivo, en la Licenciatura en Comunicación Social de la Universidad Nacional de Moreno como la del Taller de proyectos documentales transmedia, perteneciente a la Maestría en Periodismo documental de la Universidad Nacional de Tres de Febrero, fue similar. Cabe señalar que en el primer caso, el taller es una asignatura de tipo optativa, ubicada en el ciclo final de la carrera. Por ese motivo acceden a la cursada exclusivamente estudiantes de cuarto 
y quinto año. En lo que se refiere a la maestría de la UNTREF, la asignatura es de carácter optativo y abierto; pueden inscribirse no solamente estudiantes de la maestría, sino también personas con otros recorridos y trayectorias académicas.

En un primer momento se impartieron clases teóricas que daban cuenta de los principales conceptos teóricos vinculados a la cultura de convergencia, con especial énfasis en el desarrollo de las nociones de "transmedia" y "documental interactivo", además de apoyar la teoría con distintos ejemplos. En cada clase los estudiantes debían realizar distintos ejercicios y trabajos prácticos, en los que se ponían en juego el aprendizaje de estas conceptualizaciones. El primero de ellos hacía referencia a las posibilidades de adaptación a una narrativa transmedia a partir de un producto cultural preexistente. De esta manera, a partir de un ejemplo literario, cinematográfico, serie televisiva, cómic, etcétera, los estudiantes debían imaginar una posible narración transmedia y describirla en una carilla, mencionando el origen, en qué medios o plataformas podría desarrollarse, y señalar también el lugar, la temporalidad y los personajes principales de la narración. Para realizar este ejercicio, los estudiantes eligieron trabajar con ejemplos pertenecientes en muchos casos a productos tradicionales o conocidos de la cultura popular, tales como películas, series de televisión, videojuegos, como Starlancer, u obras de la literatura universal, como por ejemplo cuentos de Roberto Arlt. Estos casos eran pensados para ser desarrollados transmediáticamente en plataformas tales como sitios webs, comunidades en Facebook y Twitter, mobisodios y websodios (audiovisuales de corta duración, producidos especialmente para dispositivos móviles y/o para la web), etcétera.

La segunda actividad práctica consistía en ofrecerles una serie de fotografías y fragmentos de noticias periodísticas, que remitían a dos problemáticas y universos específicos, de los que tenían que elegir solo uno. En este caso, los estudiantes debían pensar una forma hipertextual de ligarlas, estableciendo una narrativa al respecto de estas imágenes, e indicando el tipo de contenido o formato que serviría para representar esa narrativa y para pensar una intervención interactiva que pudiera llevarse a cabo con esos materiales previamente dados. Era esencial para el debido cumplimiento del ejercicio, que apuntaba a que el estudiante pudiera reconocer una estructura hipertextual, que realizaran un esbozo de estructura o de orden en el cual iban a presentar esos fragmentos.

La primera opción hacía referencia a la trata de personas, a partir de un acontecimiento histórico. A fines del siglo XIX en la Argentina, un grupo de emigrados polacos judíos decidió constituir una extraña sociedad mutual, denominada Sociedad Israelita de Socorros Mutuos Varsovia, con el fin de "importar" desde el Este de Europa a jóvenes polacas, sobre todo de origen judío, para explotarlas en la prostitución. Dada la marginación a la cual eran sometidos 
tanto los proxenetas como sus explotadas, y el calificativo de "impuros" que les imponía su religión, se construyó un cementerio propio donde enterrarlos. Fue así como en 1906 adquirieron las tierras donde inauguraron su "camposanto". Así, más de dos mil hombres y mujeres encontraron un lugar donde dormir eternamente. Hoy este cementerio está cerrado, en estado de abandono y semi saqueado, adyacente al Cementerio Israelita de Avellaneda.

La segunda opción estaba vinculada a las dos explosiones en el cuarto reactor de la planta nuclear de la ciudad de Chernobyl, que tuvo lugar en Ucrania en 1986, que en aquel momento formaba parte de la Unión Soviética. Las explosiones esparcieron alrededor de doscientas toneladas de material radiactivo equivalente a más de cien bombas atómicas como la que explotó en Hiroshima, en ocasión de la Segunda Guerra Mundial.

En ambos casos, además de brindar la información básica y necesaria para contextualizar, se les daba también a los estudiantes testimonios y declaraciones de los protagonistas y testigos de los acontecimientos. Como ya señalé, el ejercicio apuntaba a encontrar una manera hipertextual de relacionar y ordenar una información que había sido suministrada en textos e imágenes. A partir de estos disparadores, los estudiantes se implicaron en el desarrollo de sitios web que incluían drones que recorrerían los diferentes espacios, con el fin de ofrecer una opción inmersiva para los usuarios; una suerte de tour o caminata virtual, en la que se podría recorrer una reducida proporción de los lugares; el acceso a audios y videos pertenecientes a testimonios de los protagonistas; infografías interactivas que mostraran estadísticas y diversos datos; mapas que cartografiaran las zonas; artículos periodísticos sobre las problemáticas abordadas; foros, etcétera.

Como se puede apreciar entonces, los resultados y las opciones que eligieron los estudiantes fueron muy diversas, pues se valieron de distintos recursos y procedimientos formales, que involucraban soportes, lenguajes y formatos híbridos y transdisciplinarios, lo que constituye un rasgo recurrente de las narrativas documentales transmedia.

\section{Trabajos finales: análisis de dos casos}

\section{Moreno Bitácora Histórica}

Los trabajos finales de los talleres incluyeron proyectos y resultados muy diversos. En relación a los estudiantes de la Universidad Nacional de Moreno, quiero destacar especialmente el trabajo final realizado por los estudiantes Roberto Rignola y Jorge Ibarra, denominado "Moreno 
Bitácora Histórica" (de ahora en adelante, MBH), un proyecto transmedia que aborda hechos históricos ocurridos en esa localidad. El proyecto narra tres hechos: el Vado de Paso del Rey, la Batalla del Puente Márquez y la historia del Puente Márquez. Los acontecimientos abarcan un periodo temporal que va desde el siglo XVI con el descubrimiento, a manos del colonizador español Rodrigo Ortiz de Zárate, del vado de Paso del Rey, pasando por el siglo XVIII con la construcción del Puente Márquez por Don Pablo Márquez, hasta el siglo XIX, con el enfrentamiento entre Juan Manuel de Rosas y Juan Galo de Lavalle en los alrededores del mencionado puente.

El proyecto se inserta sobre una plataforma Wix que contiene los acontecimientos históricos en una línea de tiempo, compuesta de texto, imagen y video. Esto se complementa con un mapa interactivo de las zonas específicas donde sucedieron los hechos. En la página de inicio hay una imagen más una breve descripción textual de cada hecho histórico. A su vez, al hacer clic sobre la imagen se despliega un video explicativo de lo sucedido en cada caso, que muestra piezas visuales del lugar en la actualidad, acompañadas por una narración en voz en off. También se encuentra un mapa interactivo hecho en Google Maps, donde está localizado el lugar específico en el que transcurrió cada historia, acompañado de imágenes y una breve reseña textual de lo acontecido. Aquí también encontramos los enlaces a las redes sociales Facebook e Instagram, como así también un feed de los Twitters de Rosas y Lavalle.

Otro sector importante son las secciones Acerca de $\mathrm{MBH}$ y Blog $\mathrm{MBH}$. En la primera de ellas se localiza un texto explicativo y descriptivo del proyecto de "Moreno Bitácora Histórica", al igual que ciertos datos sobre los desarrolladores del producto e información de contacto. En el blog se encuentran distintas entradas gráficas que combinan texto e imagen fija (y en algunos casos también video) de historias relacionadas con el partido de Moreno o con acontecimientos referidos a algunos de los personajes nombrados en los tres relatos principales del transmedia documental. Por ejemplo, en un inicio se narra la historia de la creación del dulce de leche, el paso de Charles Darwin por Moreno, la historia del Camino Real y la biografía de Juan Manuel de Rosas. Además, el blog cuenta con la posibilidad de recibir comentarios, enlaces a redes sociales y la oportunidad para que los propios usuarios puedan subir contenidos y escribir sus propias historias. Para colaborar en la construcción del universo narrativo del documental, los estudiantes se valieron también de recursos como imágenes del armamento, vestimenta, comida y demás objetos de la época, al igual que el uso de efectos sonoros y de musicalización que representaran lo sucedido.

\section{Mapa de contenido y gráfico del ecosistema mediático}




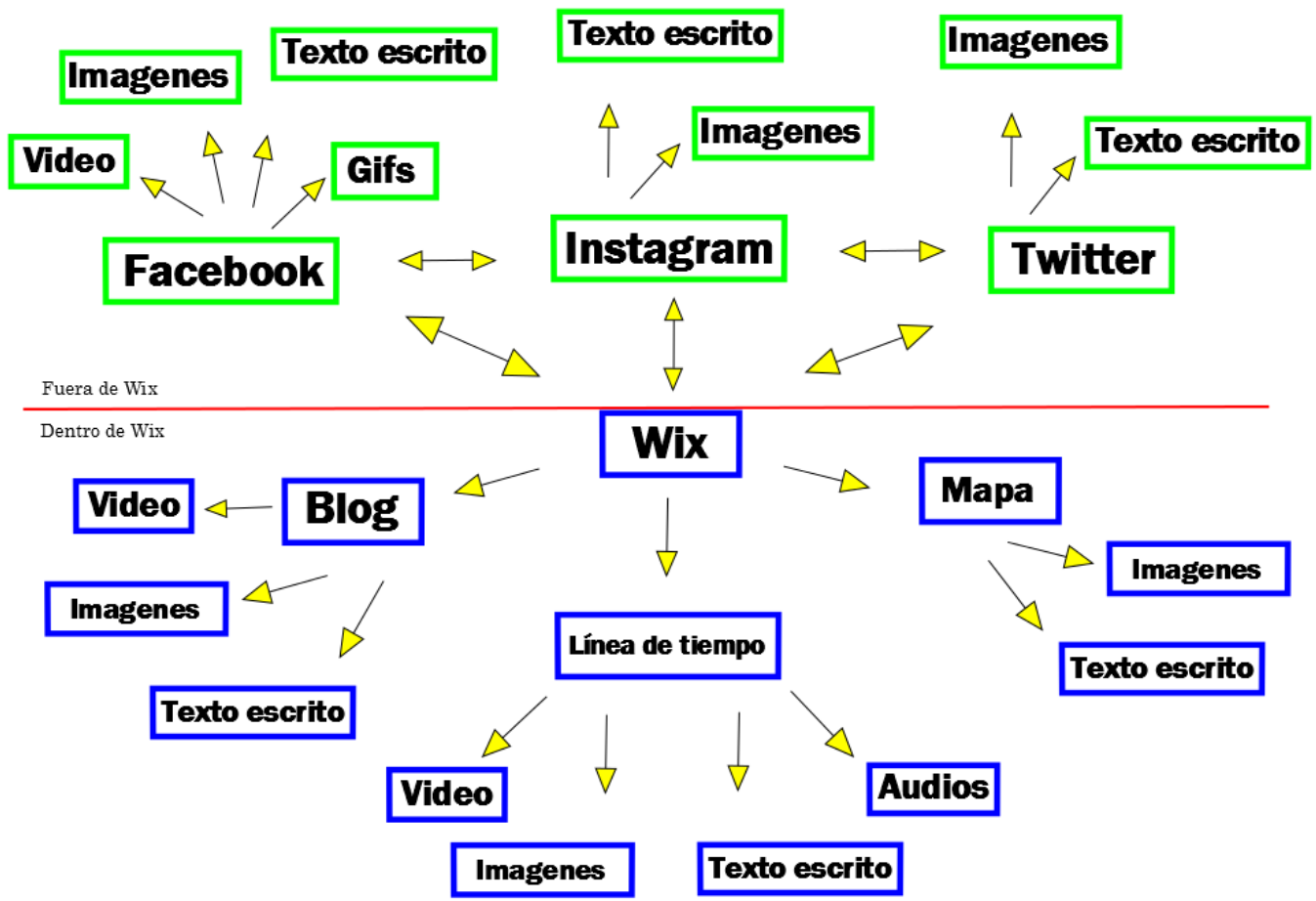

Figura 1: Mapa de contenido y gráfico del ecosistema mediático. Rignola e Ibarra, 2016. 


\section{Mapa de contenido (página de inicio)}

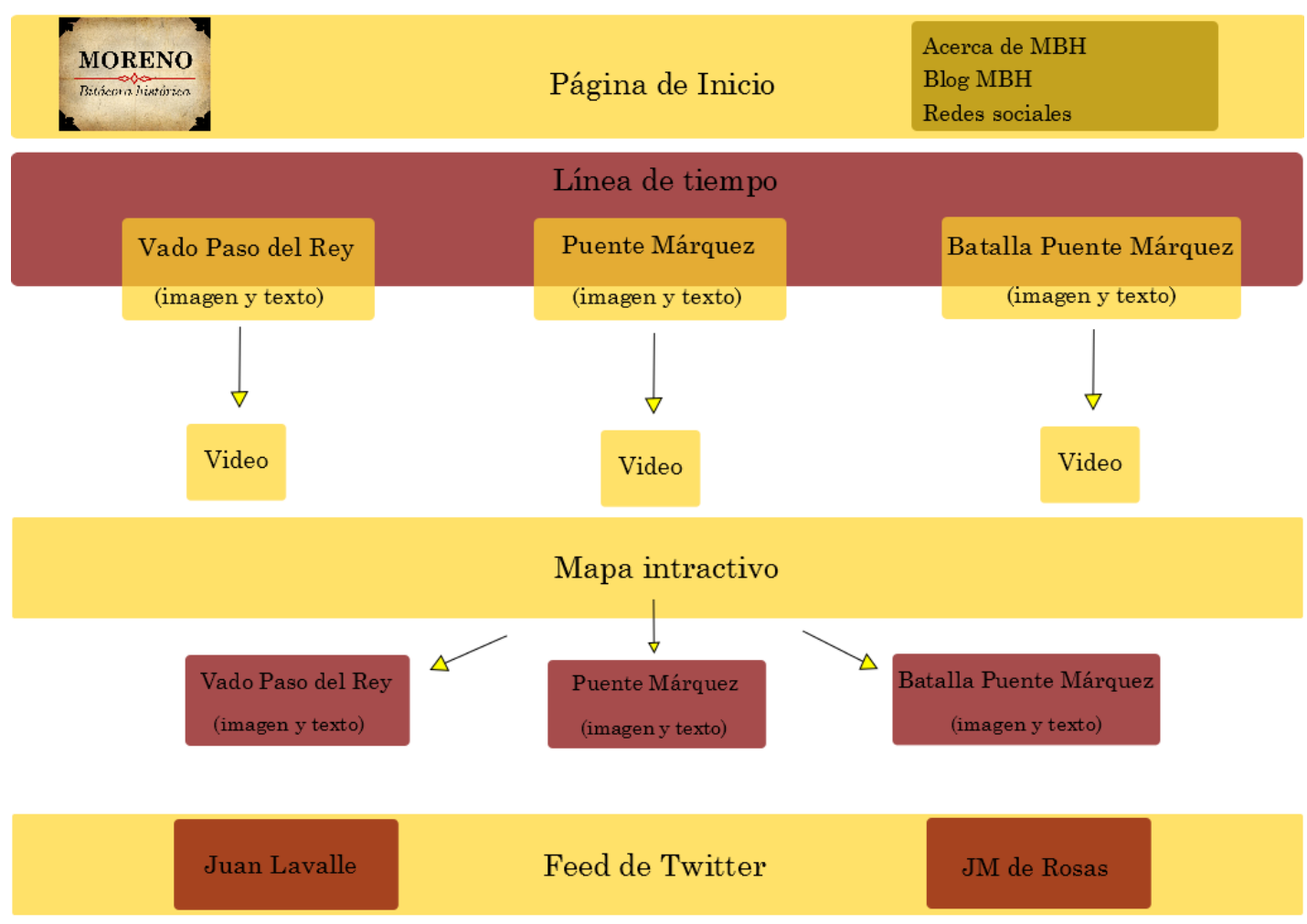

Figura 2: Mapa de contenido (página de inicio). Rignola e lbarra, 2016. 


\section{Mapa de contenido (Blog MBH)}

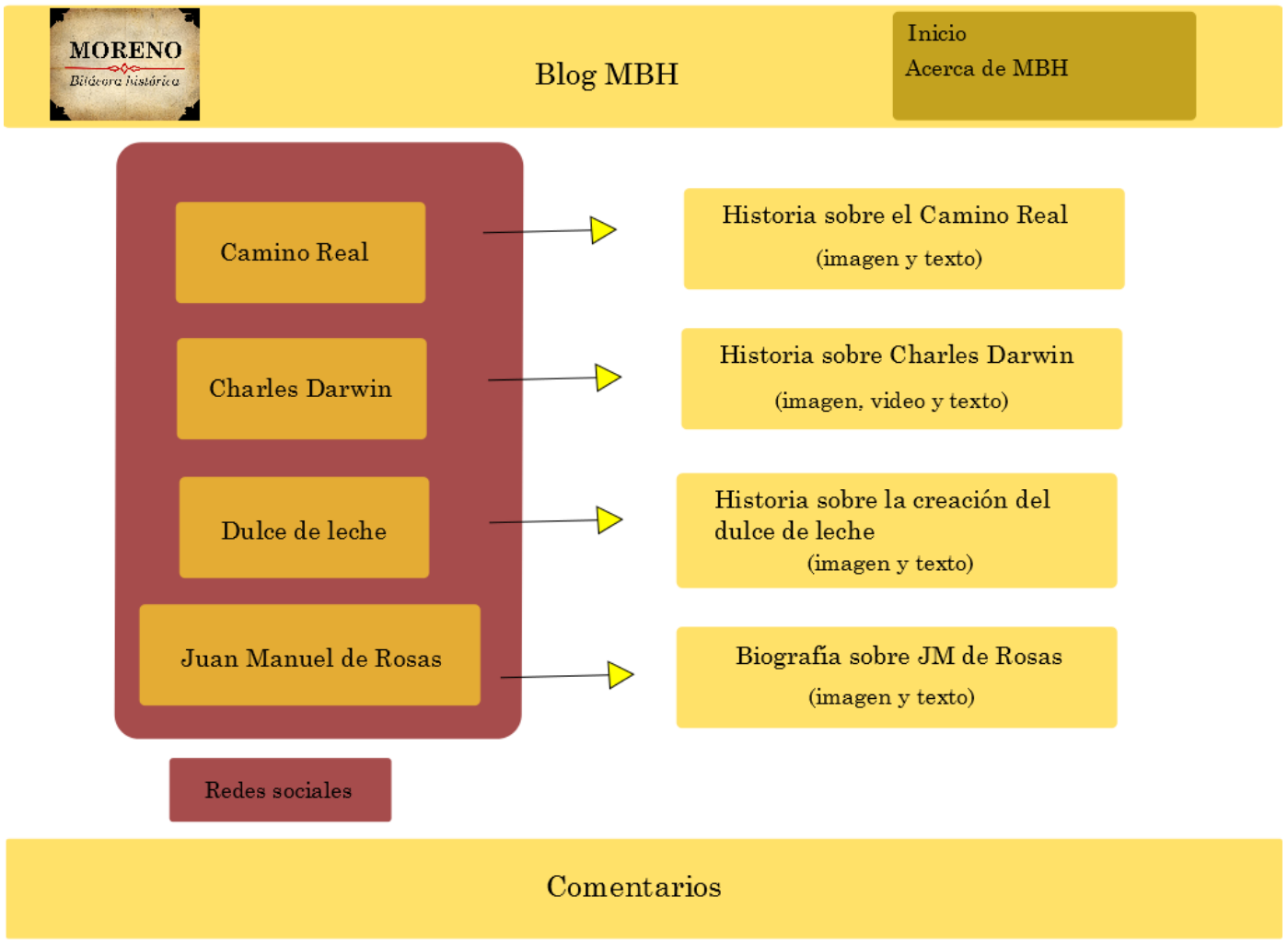

Figura 3: Mapa de contenido (Blog MBH). Rignola e Ibarra, 2016.

Una de las características más interesantes de este trabajo es el uso de las redes sociales, que funcionaron tanto a modo de interacción con los usuarios como para la difusión de los contenidos, con el fin de ampliar el universo narrativo del proyecto. Instagram fue usado para subir contenido fotográfico de vestimentas, comidas, armamento y demás elementos de esa época, al igual que imágenes que los usuarios suministraban. En Twittermse crearon perfiles de dos personajes históricos, Juan Manuel de Rosas y Juan Lavalle, protagonistas de MBH, quienes combatían dialéctica y retóricamente en tiempo real a través de la red social, como si estuviéramos situados en el período de tiempo de los relatos. Por su parte, Facebook se aprovechó primariamente como canal de difusión de los materiales de las otras plataformas, pero a su vez los estudiantes generaron contenido propio que apuntaba a un aspecto lúdico (dado por la inclusión de trivias, crucigramas, laberintos, sopa de letras) y humorístico (gifs, hashtags, etcétera). Así, MBH se valió de distintos recursos narrativos, formatos, lenguajes y plataformas para dar a conocer hechos históricos relevantes ocurridos en la localidad de 
Moreno, muchos de ellos desconocidos incluso por los propios habitantes de la zona, quienes de esa manera vieron resignificado su lugar de origen, gracias a este trabajo de comunicación histórica.

\section{Sáhara Occidental: la guerra olvidada}

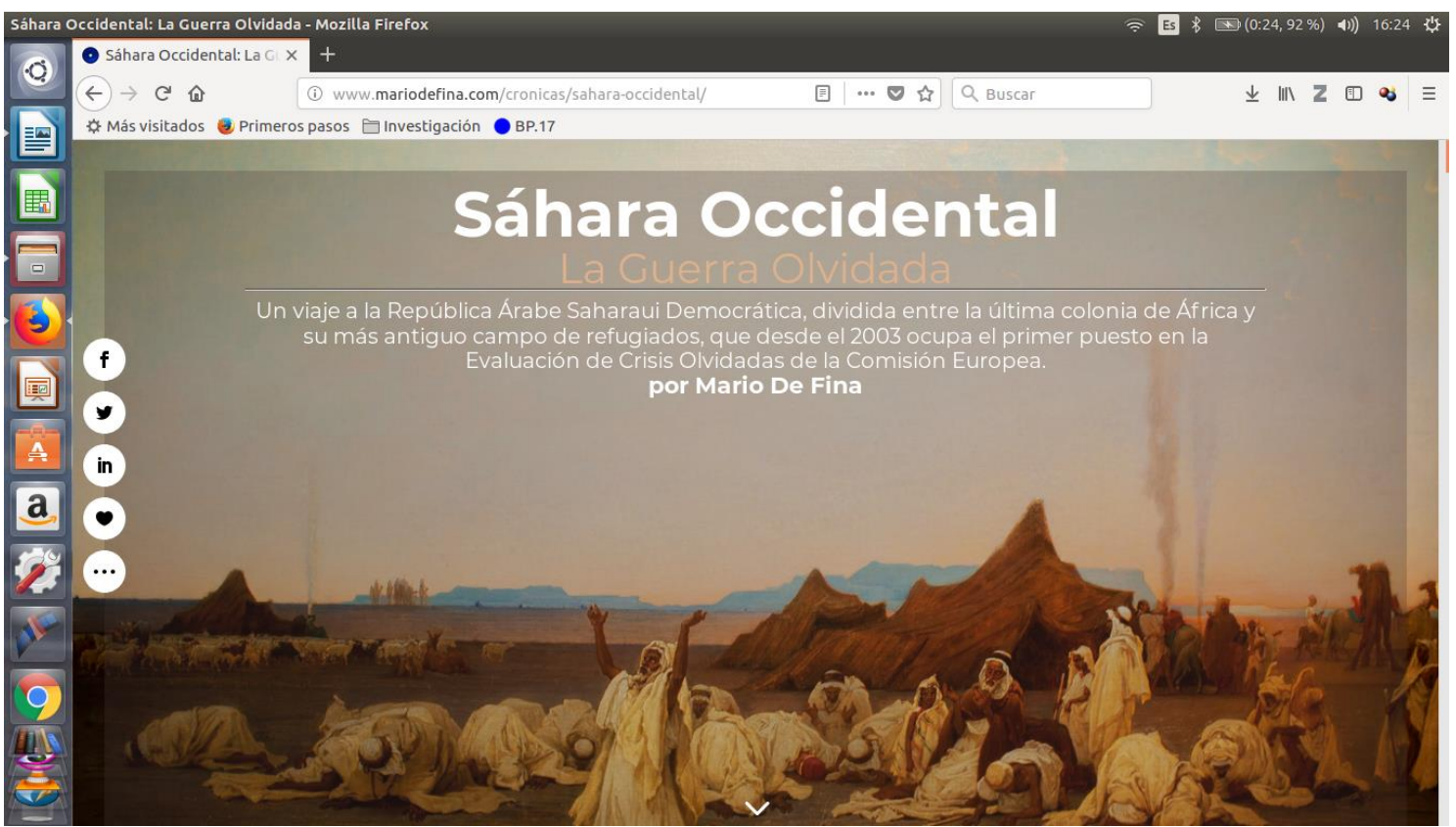

Figura 4: Página de inicio de la crónica multimedial: “Sáhara Occidental: La Guerra Olvidada”. De Fina, 2016.

En el marco del taller que dicté en la maestría en Periodismo documental de la UNTREF, Mario De Fina continuó y profundizó el desarrollo de su crónica multimedial "Sáhara Occidental: La Guerra Olvidada", que constituye, tal como él mismo lo define: "Un viaje a la República Árabe Saharaui Democrática, dividida entre la última colonia de África y el más antiguo campo de refugiados, que desde el 2003 ocupa el primer puesto en la Evaluación de Crisis Olvidadas de la Comisión Europea" (De Fina, 2016). Cabe señalar que este proyecto fue premiado por el Posgrado en Periodismo de Investigación que la Editorial Perfil organiza junto con la Universidad del Salvador (USAL), que ofrece el galardón de publicar la investigación realizada en algún medio de la Editorial Perfil y otorga la Beca José Luis Cabezas, una beca completa por la que formó parte del Ciclo 2017 del mencionado posgrado. De Fina estudió Licenciatura 
en Historia en la Universidad Nacional de Tres de Febrero y realizó distintos posgrados de Periodismo y Ciencias Sociales en universidades de Argentina y Europa. A la hora de otorgar el premio, el jurado destacó "la alta calidad narrativa, la rigurosidad periodística y el acceso a fuentes e información" del trabajo ganador.

De Fina viajó a El Aaiún, la ciudad más importante del Sáhara Occidental, perteneciente a la autoproclamada República Árabe Saharaui Democrática, que la considera su capital, pero que en la práctica se encuentra ocupada y administrada por Marruecos, como la mayor parte de ese territorio. Fue el descubrimiento de grandes yacimientos de fosfato el que comenzó a proveer de sentido a la enorme empresa colonial llevada adelante en primer lugar por los españoles, y lo que motivó la construcción de la actual capital, El Aaiún, a mediados del siglo pasado (De Fina, 2016). El periodista argentino narra en su crónica multimedia diversos encuentros y entrevistas que realizó con representantes del Frente Polisario en los Territorios Ocupados, que lucharon contra las fuerzas armadas de Marruecos y Mauritania para la descolonización y la independencia de la antigua colonia española del Sáhara Occidental desde 1975 hasta 1991, en lo que se conoció como la guerra del Sáhara Occidental, que tuvo como consecuencias la retirada española en 1976, (teniendo en cuenta que el Frente Polisario había luchado contra las fuerzas españolas desde su creación en 1973), la retirada de Mauritania en 1979 y un acuerdo de alto el fuego con Marruecos en 1991. No obstante y a pesar de esto último, la mayor parte del territorio aún se mantiene bajo control marroquí. El Frente Polisario fue primero conocido, en la época de la guerra, como Frente Popular de Liberación de Saguia-el Hamria y Río de Oro, y es un movimiento de inspiración marxista que ejercía la lucha revolucionaria para conseguir la libre determinación de su pueblo.

De Fina narra minuciosamente las técnicas de vigilancia y control a las que es sometido por las autoridades marroquíes debido a su condición de occidental, en una zona en la que no se admiten periodistas ni fotógrafos de ningún tipo. En su trabajo, el periodista argentino ofrece cifras escalofriantes:

se calcula que de los 500 mil habitantes del Sáhara Occidental, apenas el $20 \%$ son saharauis, pero no todos son disidentes: muchos abrazaron la causa marroquí gracias a los subsidios a los servicios y ayudas económicas ofrecidas por el Estado para "marroquinizar" a la población. Los que se resisten son sometidos a las violentas y salvajes golpizas en las calles que no distinguen entre hombres, mujeres o niños, le siguen las torturas en las prisiones y la falta de atención médica para quienes atenten contra el reino (De Fina, 2016). 
De Fina recoge también testimonios de presos políticos y torturados por las fuerzas marroquíes, muchos de ellos exiliados en las Islas Canarias, pertenecientes a España. Y se dirige también a los campos de refugiados de la provincia de Tinduf, ciudad ubicada al suroeste de Argelia. Estos campos están habitados por refugiados saharauis y fueron llamados con los nombres de las ciudades de Sáhara Occidental: El Aaiún, Auserd, Smara y Dajla.

Utilizando una plataforma paga de Wordpress y redes sociales como Facebook, Twitter, Linkedln e Instagram, y valiéndose del género subjetivo de la crónica, que permite una gran posibilidad de empatía e inmersión, además de valerse de recursos como galerías de imágenes, videos, audios, mapas, fotografías en 360 grados y dibujos, que obligan al usuario a navegar verticalmente, De Fina construye este impactante relato multimedial que da visibilidad a una realidad largamente silenciada y oculta, al menos vista desde la perspectiva de Occidente.

\section{A modo de cierre}

En este trabajo he intentado reflexionar sobre los usos y las posibilidades que ofrecen las narrativas transmedia a partir de dos experiencias educativas que llevé adelante en la Universidad Nacional de Moreno y en la Universidad Nacional de Tres de Febrero. Se trata de espacios curriculares muy diferentes, teniendo en cuenta que en el primer caso el taller formaba parte de la oferta curricular de grado, mientras que el segundo tuvo lugar en el marco de una maestría, y que las trayectorias, saberes y disciplinas de los estudiantes eran, en ambos casos, divergentes, si bien tenían el trasfondo común del periodismo y la comunicación. En el caso de "Moreno Bitácora Histórica", los estudiantes supieron utilizar variada y complementariamente diversas redes sociales como Instagram, Twitter y Facebook, con el fin de generar una comunidad de usuarios que siguiera las narrativas creadas por los realizadores y que desarrollara a la vez contenido propio, en el marco de un proyecto que se propone rescatar la impronta y el derrotero de importantes personajes de la historia nacional, ubicados y resignificados dentro de acontecimientos pocos conocidos que tuvieron lugar en el partido de Moreno. El proyecto no está exento de narrativas paródicas y humorísticas, que apuntan a rescatar el costado humano de próceres como Juan Manuel de Rosas y Juan Lavalle, con el objetivo de producir empatía e identificación en la comunidad educativa perteneciente a la universidad local. La macrohistoria o "Historia con mayúsculas" es resignificada así a partir de anécdotas y momentos íntimos pertenecientes a la microhistoria y a la vida cotidiana de estas 
personalidades. A través de este tipo de recursos, estrategias y procedimientos narrativos, el proyecto logró interpelar a los estudiantes de la carrera de comunicación, quienes de esta manera pudieron revalorizar los lugares por los que transitan todos los días.

En lo que se refiere a "Sáhara Occidental: la guerra olvidada", la crónica multimedial desarrollada por el periodista Mario De Fina se vale de diversos formatos, soportes y lenguajes, con el fin de otorgar visibilidad y escucha social a una problemática geopolítica internacional que permanece oculta en la agenda pública global. El trabajo que llevamos adelante en conjunto en el marco del taller que dicté para la maestría en Periodismo documental de la Universidad Nacional de Tres de Febrero, supuso dotar a la crónica de instancias y caminos narrativos propios del transmedia, con el fin de enriquecer expresivamente el desarrollo de investigación escrito y fotográfico que De Fina ya había realizado.

Este artículo se propuso entonces señalar, a través del poder de la ejemplificación, la instancia de gran apertura a nuevos formatos, técnicas, modalidades de navegación e interactividad, en suma, de enorme experimentación, que el transmedia documental tiene en la actualidad, no sólo en el campo mediático sino muy especialmente en la instancia educativa, en la que las universidades públicas juegan un rol determinante. Esta apertura no hará más que intensificarse en un presente cada vez en mayor medida hipermediático. Por lo que los desafíos dentro de las aulas, en lo que se refiere a las narrativas transmedia, estarán a la orden del día, y la formación de docentes y estudiantes que aprendan a dominar estas narrativas será entonces crucial.

\section{Bibliografía}

De Fina, M. (2016). Sáhara Occidental: la guerra olvidada. Maestría en Periodismo documental, Universidad Nacional de Tres de Febrero, Buenos Aires. Recuperado de http://www.mariodefina.com/cronicas/sahara-occidental/

Gifreu Castells, A. (2013). El documental interactivo como nuevo género audiovisual. (Tesis doctoral). Universidad Pompeu Fabra, Barcelona. Recuperado de www.doc.ubi.pt/14/teses_arnau_castells.pdf.

Grandío-Pérez, M. (2016). El transmedia en la enseñanza universitaria. Análisis de las asignaturas de educación mediática en España (2012-2013). Palabra Clave, 19(1), pp. 85-104. Recuperado de http://www.redalyc.org/articulo.oa?id=64943974004 
Jenkins, H. (2008). Convergence culture. La cultura de la convergencia de los medios de comunicación. Barcelona, España: Paidós.

Rignola, R. e Ibarra, J. (2016). Moreno Bitácora Histórica. Licenciatura en Comunicación Social, Universidad Nacional de Moreno, Buenos Aires. Recuperado de http://donjuanmanuelderos. wixsite.com/morenobh

Rincón, O. (2013). Las narrativas colabor-activistas: las identidades otras como innovación mediática. Revista Dixit, 19, pp. 4-15. doi: https://doi.org/10.22235/d.v0i19.369

Scolari, C. (2013). Narrativas transmedia. Cuando todos los medios cuentan. Madrid, España: Deusto Ediciones. 